\title{
Direct to consumer advertising of prescription medicines in New Zealand to retain market share
}

\author{
Sashika Samaranayaka \\ School of Pharmacy and Faculty of Medicine, University of Otago \\ James A. Green ${ }^{1}$ \\ School of Pharmacy, University of Otago \\ Health Research Institute (HRI) and School of Allied Health, University of \\ Limerick
}

Direct to consumer advertising (DTCA) of prescription medicine is only practised in New Zealand and USA. This study attempted to find a link between the rate of advertising and the rate of dispensing, and subsequently explored the timing of advertising relative to the arrival of generic equivalents to the advertised brand. Nine magazine titles were exhaustively hand searched from January 2005 to December 2009 for advertisements for prescription medicines. For a subset of advertised medicines, subsidised dispensing rates of those medicines and equivalent products were obtained from the New Zealand Ministry of Health/PHARMAC for the same period. The rates of advertising were then compared with the rates of dispensing. No direct link was observed between the rate of advertising and the rate of dispensing of that particular medicine. However, almost all advertising occurred around the introduction of subsidy for competitor products. This suggests that medicine advertising is intended to act defensively, to preserve market share. This type of medicine advertising has not been observed previously, and does not offer any clear educational benefit to the consumer, and instead may lead to out of pocket spending where a cheaper equivalent medicine is available.

\section{Introduction}

New Zealand and USA are the only two developed countries that allow Direct to Consumer Advertising (DTCA) of prescription medicines. Change has been considered in Canada and Europe (Mintzes, 2006) and there has been considerable debate around this advertising in New Zealand and USA (Coney, 2002; Hoek \& Maubach, 2007; Klara, Kim, \& Ross, 2018; Kmietowicz, 2003; Norris et al., 2005; Scott, Stanford, \& Thompson, 2004).

Proposed benefits for DTCA include that it may empower consumers by providing information on what medicines are available (Calfee, 2002) and that it may educate consumers on their health conditions and related medications (Coney, 2002; Young \& Cline, 2005). This can help people to recognise symptoms,

1 Correspondence to \ames.Green@ul.ie, School of Allied Health and Health Research Institute (HRI), Health Sciences Building, University of Limerick, Limerick V94 T9PX, Ireland. 
seek medical advice and get diagnosed earlier, therefore saving on medical costs in the future. Greater consumer awareness might also assist the patients to become more actively involved in their consultations with their doctors (Menon, Deshpande, Perri, \& Zinkhan, 2003) and possibly increase patient compliance, because it may reinforce existing knowledge (Hoek \& Maubach, 2007) and 'remind patients to refill their prescriptions' (Menon et al., 2003).

Advocates for DTCA also acknowledge the benefits for the pharmaceutical companies from being able to "attach missing information to their brands and to disseminate that information to increase brand demand" (Calfee, 2002). They argue that if DTCA does not lead to inappropriate prescribing, then it does not create a problem. In the US, $32 \%$ of the consumers had talked with a health professional about an advertised medicine (Calfee, 2002), whereas the rate in New Zealand is around half that (Zadeh, Robertson, \& Green, 2017). However, critics argue there is a lack of evidence for DTCA having these positive health benefits. (Almasi, Stafford, Kravitz, \& Mansfield, 2006; Lexchin \& Mintzes, 2002).

In contrast, critics of DTCA argue that rather than providing appropriate health information, it is persuasive and biased, aiming to increase sales (Coney, 2002; Frosch, Grande, Tarn, \& Kravitz, 2010; Gilbody, Wilson, \& Watt, 2005). Advertising is not altruistic, especially when the goal of DTCA is "simply to create market recognition of a brand, inform and to persuade"(Coney, 2002). Of concern, two studies in New Zealand shows that vulnerable consumers (Zadeh et al., 2017) and those with less healthy lifestyles - lower levels of physical activity and higher levels of unhealthy eating, alcohol and illegal substance use - (Zadeh, Robertson, \& Green, 2019) may be more likely to respond to DTCA.

Research looking at whether the health information in the advertisements is accurate has found some advertisements to be 'biased and misleading', as the advertisements focus more on the benefits than the risks and they rarely provide information about the success rates of the treatment or alternative treatments. (Almasi et al., 2006; Bell, Wilkes, \& Kravitz, 2000; Calfee, 2002; Kaphingst, DeJong, Rudd, \& Daltroy, 2004; Scott et al., 2004; Young \& Cline, 2005).

The original aim of this project was to explore associations between the rate of dispensing and the rate of advertising. A subsequent aim was derived from the data, to explore the timing of DTCA for a particular product, relative to (generic) competitors.

\section{Sampling}

\section{Method}

Previous research had identified New Zealand magazines that contained prescription medicine advertisements (Cheong \& Green, 2019). Sixty magazine titles were identified from lists of New Zealand magazines. From this list, two pseudorandom issues from 2005 and 2006 were searched. Nine titles were identified as containing medicine advertisements, and all the remaining issues of 
those magazine titles were searched ${ }^{2}$. This sample was then extended for this project searching the same magazine titles from 2007 through 2009, giving a total of five years of magazine advertisements. Advertisements were scanned, and additional details were recorded (see data on https://osf.io/8nfuz/).

\section{Advertising and dispensing rates}

The number of times each medicine was advertised each month was calculated. For one quarterly publication, the ad was counted in the first month of the season (i.e., spring $=$ September, winter $=$ June, summer $=$ December, autumn $=$ march). Due to some lost paper records, only the year of publication is known for a small number of advertisements from 2005 and $2006(n=28$, but only four of these were for subsidised medicines reported in the analyses here).

In New Zealand, dispensing rates are only centrally recorded for medicines subsidised by the government's medicine buying agency (PHARMAC). Therefore, we were only able to access dispensing rates for subsidised medicines, leaving an incomplete picture. For most advertised medicines that were subsidised, information on dispensing for each month from January 2005 to December 2009 was obtained from the Ministry of Health/PHARMAC 3. Additionally, dispensing information was also obtained for any other subsidised medicines that contained the same active ingredient or were substantially similar in purpose (usually a generic with the same active ingredient).

\section{Advertising rate}

\section{Results}

A total of 173 advertisements were found for prescription medicines (summary in Table 1). DTCA was most numerous in so-called women's magazines (New Zealand Woman's Weekly n= 28, Woman's Day $n=42$.

\footnotetext{
2 In the original project, the Australian Womens' Weekly was excluded, as DTCA is banned in Australia. However, subsequent to developing this project, we discovered that this title has a separate NZ edition with some NZ content and advertisements, including DTCA. One included title, SHE, stopped publishing after 2006.

${ }^{3}$ Some medicines were excluded, for reasons that are not documented. We will request this data and update when it is available.
} 
Table 1. Number of prescription medicine advertisements found in each magazine title by year

\begin{tabular}{|c|c|c|c|c|c|c|}
\hline \multirow[t]{2}{*}{ Magazine } & \multicolumn{6}{|c|}{ Number of advertisements by year } \\
\hline & 2005 & $2005 / 6^{1}$ & 2006 & 2007 & 2008 & 2009 \\
\hline Diabetes & 0 & 0 & 3 & 6 & 4 & 0 \\
\hline New Idea & 5 & 3 & 2 & 4 & 4 & 0 \\
\hline Next & 8 & 7 & 6 & 1 & 1 & 6 \\
\hline North and South & 4 & 0 & 0 & 0 & 0 & 3 \\
\hline NZ Listener & 9 & 0 & 0 & 2 & 6 & 0 \\
\hline NZ Woman's Weekly & 0 & 0 & 7 & 8 & 1 & 12 \\
\hline $\mathrm{SHE}^{2}$ & 3 & 0 & 0 & 0 & 0 & 0 \\
\hline Woman's Day & 15 & 13 & 1 & 4 & 9 & 13 \\
\hline Your Home \& Garden & 0 & 0 & 0 & 0 & 0 & 2 \\
\hline Your House and Garden ${ }^{3}$ & 0 & 0 & 0 & 1 & 0 & 0 \\
\hline \multirow{2}{*}{\multicolumn{7}{|c|}{$\begin{array}{l}\text { Notes: }{ }^{1} \text { For some advertisements, it was not possible to determine if they were } 2005 \text { or } 2006 \\
{ }^{2} \text { SHE magazine was not published after } 2006 \text {. } \\
{ }^{3} \text { No such title exists. This is either another Your Home \& Garden or NZ House and Garden. } \\
\text { We requested dispensing data for the subsided medicines in Table 2, along } \\
\text { with any other products that had the same active ingredient that were also } \\
\text { subsidised. For reasons that were not recorded, we did not request dispensing } \\
\text { data for the following advertised medicines (noting that some may not have been } \\
\text { subsidised, so no data may have been available): Arimidex (anastrozole), } \\
\text { Cyklokapron, (tranexamic acid), Daivonex, (calcipotriol), Lantus (insulin } \\
\text { glargine), Novo Rapid (insulin aspart), Serevent (salmeterol), Tamiflu } \\
\text { (oseltamivir), Topamax (topiramate), Yasmin (combined oral contraceptive with } \\
\text { ethinylestradiol). }\end{array}$}} \\
\hline & & & & & & \\
\hline \multicolumn{7}{|c|}{ Table 2. Advertised medicines, their active ingredients, and generic equivalents. } \\
\hline Advertised medicine & \multicolumn{3}{|l|}{ Active } & \multicolumn{3}{|c|}{ Generic versions } \\
\hline Actos & \multicolumn{3}{|c|}{$\begin{array}{l}\text { pioglitazone (for Type } 2 \\
\text { diabetes }\end{array}$} & \multicolumn{3}{|c|}{$\begin{array}{l}\text { To be updated in next } \\
\text { version }\end{array}$} \\
\hline Imigran & \multicolumn{3}{|c|}{ sumatriptan (migraines) } & \multicolumn{3}{|c|}{ Arrow-sumatriptan } \\
\hline Lamictal & \multicolumn{2}{|c|}{$\begin{array}{l}\text { Lamotrigine } \\
\text { convulsant) }\end{array}$} & (anti- & \multicolumn{3}{|c|}{$\begin{array}{l}\text { Arrow-lamotrigine, } \\
\text { Logem, Mogine }\end{array}$} \\
\hline Losec & \multicolumn{2}{|c|}{$\begin{array}{l}\text { omepraz } \\
\text { reflux) }\end{array}$} & gastric & \multicolumn{3}{|c|}{ Dr Reddy's Omeprazole } \\
\hline Salamol & \multicolumn{3}{|c|}{ Salbutamol (asthma) } & \multicolumn{3}{|c|}{ Is generic (see Ventolin) } \\
\hline Seretide & \multicolumn{3}{|c|}{$\begin{array}{l}\text { Fluticasone } \\
\text { salmeterol (asthma) }\end{array}$} & \multicolumn{3}{|c|}{$\begin{array}{l}\text { To be updated in next } \\
\text { version }\end{array}$} \\
\hline Ventolin & \multicolumn{3}{|c|}{ Salbutamol } & \multicolumn{3}{|c|}{ Salamol, Respigen } \\
\hline
\end{tabular}




\section{Timing of medicines advertisements}

Monthly dispensing and advertising rates were co-plotted on a graph to explore whether advertising appeared to change rates of dispensing (see next section for this comparison). However, as the following figures show, a notable and unexpected finding was the timing of the DTCA - almost always around the time that a generic competitor was subsidised.

For example, most advertising for Losec (omeprazole) occurred around in 2008 and early 2009 as Losec was replaced by Dr Reddy's Omeprazole as the subsidised medicine (Figure 1).

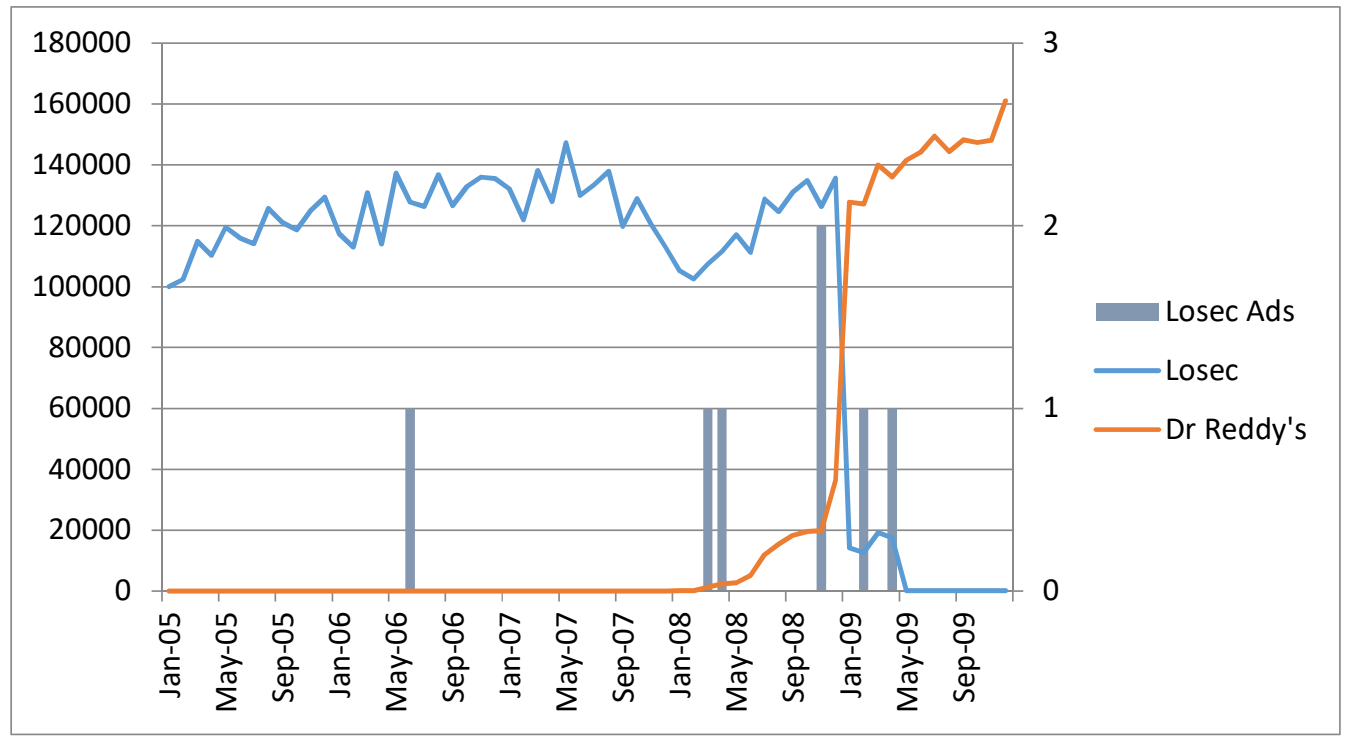

Figure 1. Volume of subsidised omeprazole (Losec and Dr Reddy's) dispensed by month compared to Losec advertising. 
Similarly, for Ventolin (salbutamol), it was advertised just after the introduction of Salamol, and then again just after the introduction of Respigen (Figure 2). Also of note, Salamol was the only generic product we observed being advertised, which was at the time of its introduction. Ventolin is also slightly unusual in that it retained its' subsidised status alongside the new generic medicines.

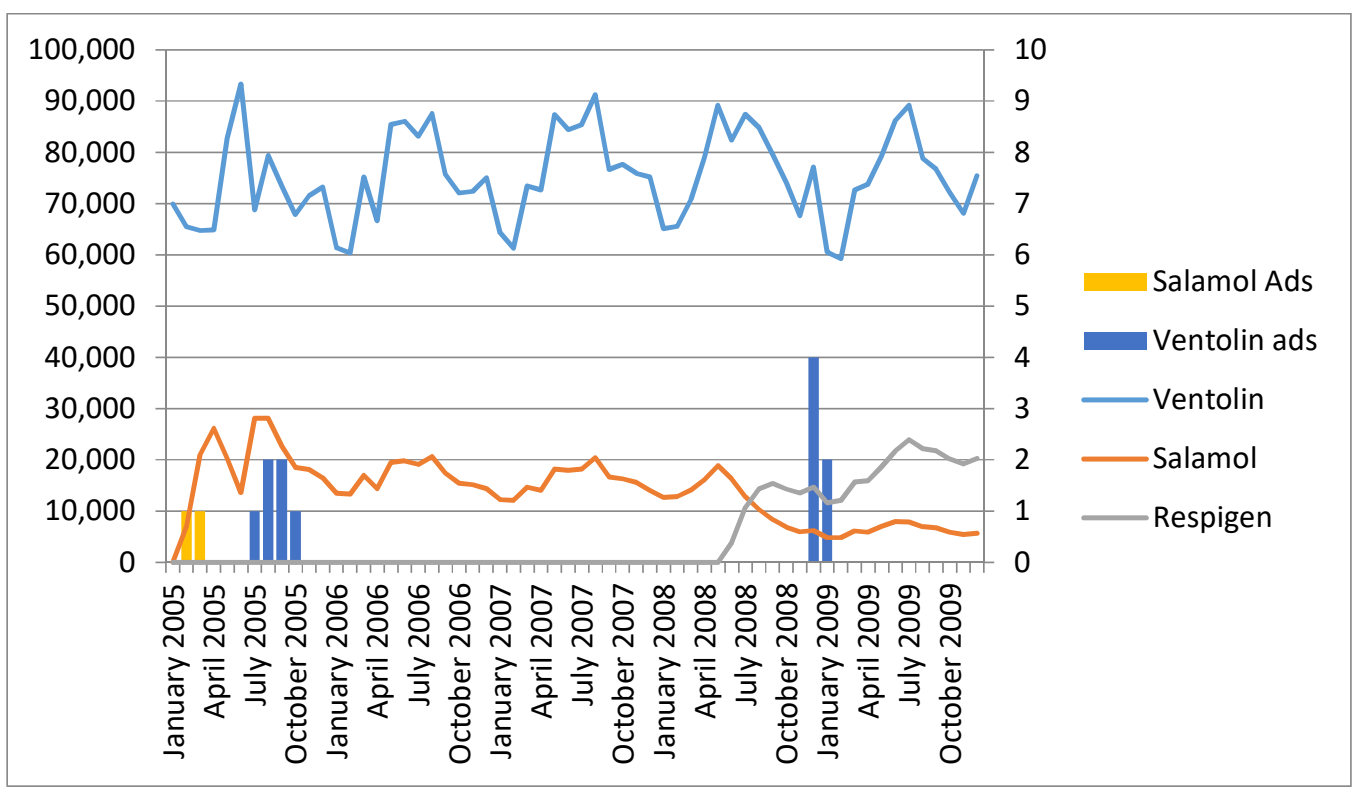

Figure 2. Volume of subsidised salbutamol (Ventolin, Salamol and Respigen) dispensed by month compared to Ventolin and Salamol advertising.

Imigran (sumatriptan) shared an advertisement with Ventolin and Lamictal, and was also advertised after two generic medicines were also subsidised (Figure 3). Notably, these advertisements explicitly suggested to patients/consumers to ask for the product by name.

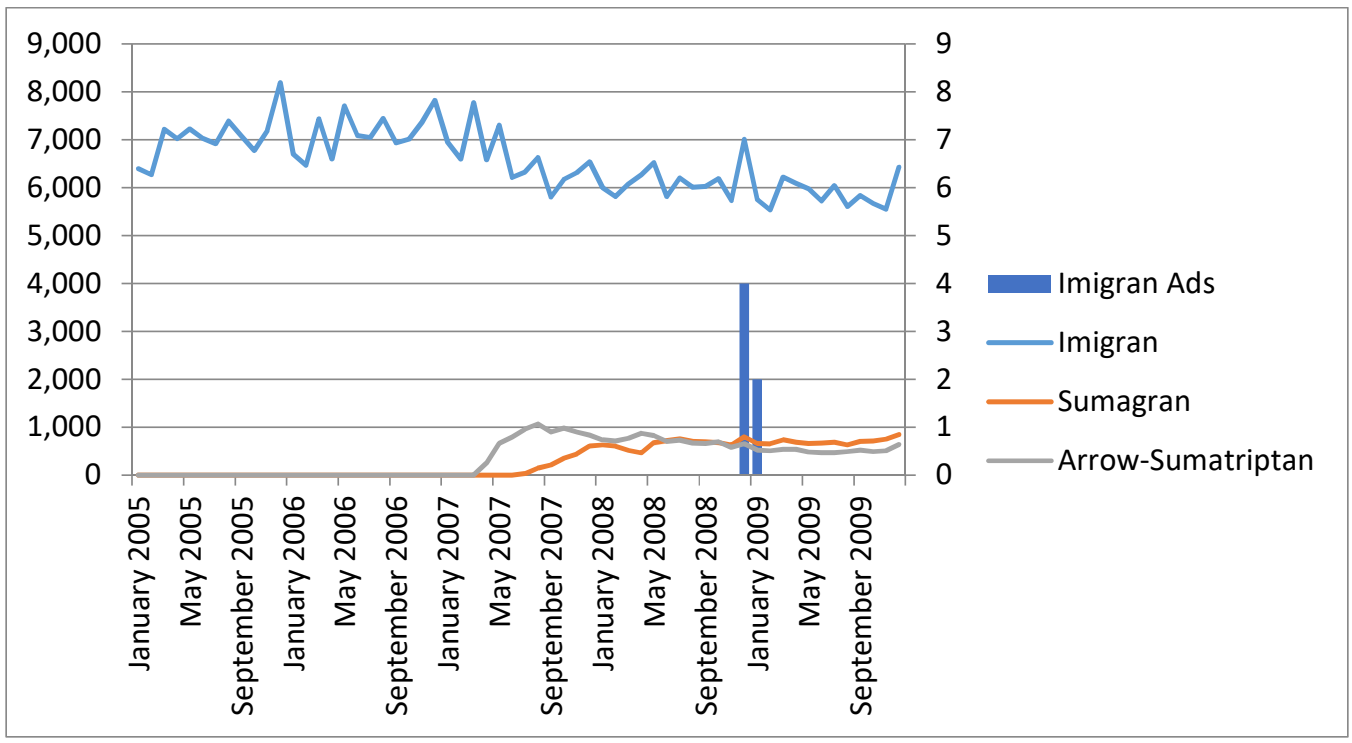

Figure 3. Volume of subsidised sumatriptan (Imigran, Sumagran and ArrowSumatriptan) dispensed by month compared to Imigran advertising. 
Lamictal (lamotrigine) was the third product to feature in the ask-forthese-products-by-name advertisements, again after generic medicines were subsidised (Figure 4).

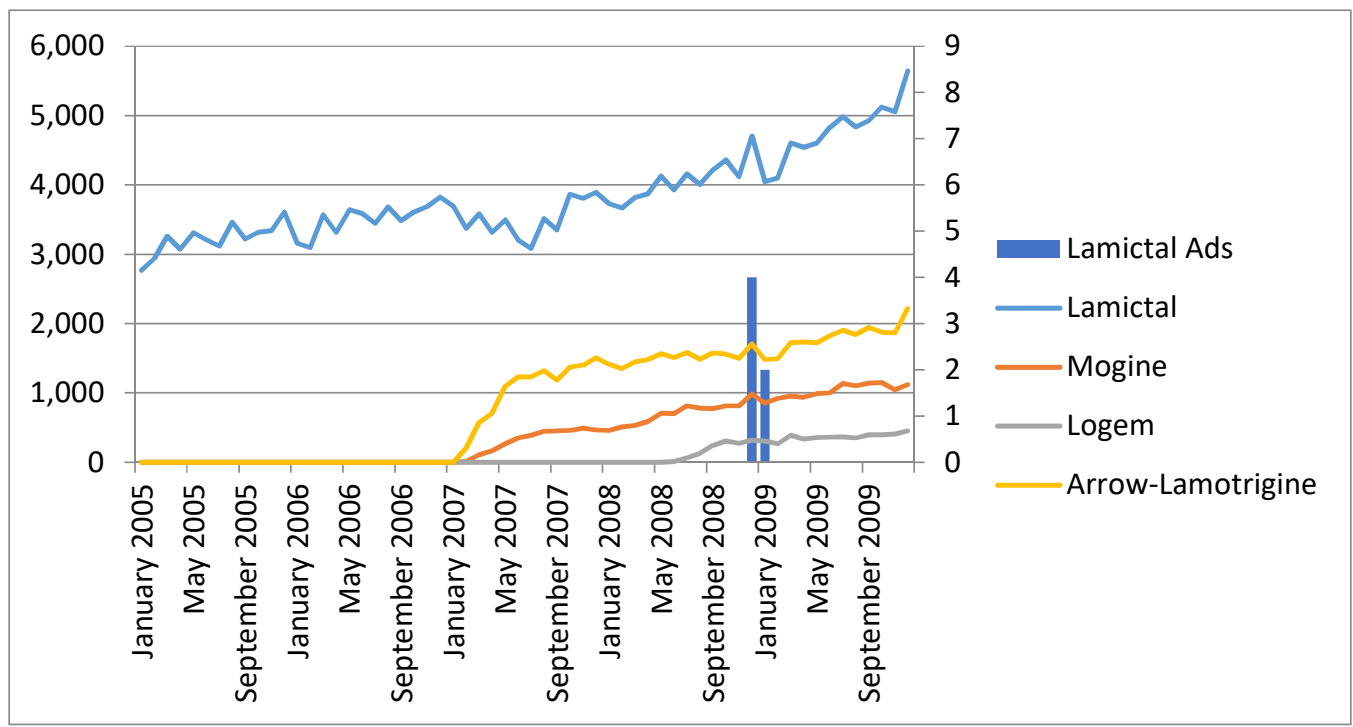

Figure 4. Volume of subsidised lamotrigine (Lamictal, Mogine, Logem and ArrowLamotrigine) dispensed by month compared to Lamictal advertising.

\section{Impact of advertising on dispensing rates}

Based on the figures presented in the prior section, we saw little evidence for any noticeable effect of the DTCA on the rate of dispensing of subsidised medicines. For example, in Figure 1, Dr Reddy's Omeprazole appears to completely replace Losec at approximately the same level of monthly dispensing. Aside from the obvious seasonal trend in Ventolin, the dispensing is remarkably static over the five years. As for Lamictal and Imigran, there is no obvious change in the trend over time around the DTCA.

\section{Discussion}

Unexpectedly, magazine advertising of prescription medicines to New Zealand consumers almost always coincided with a generic equivalent being subsidised by the New Zealand government. This is surprising, because one of the supposed benefits of DTCA is that it helps to make consumers make informed decisions about their medicines, and perhaps highlights new treatments and might help trigger appropriate medication use (Calfee, 2002; Coney, 2002; Menon et al., 2003). However, this timing seems to suggest that the DTCA instead aims to preserve market share for the innovator (brand) medicine when a generic competitor is subsidised. Despite branded medicines being preferred to generic medicines (Colgan et al., 2015), these medicines should be interchangeable. So rather than serving an education role, these medicines instead encourage out-ofpocket medicine expenditure for no obvious benefit. In fact, the wording of some of the advertisements "There is no need to change", has no clear educational 
value, and only serves to preserve market share. This finding is of further concern in light of recent work suggesting that DTCA is most influential with more vulnerable consumers (Zadeh et al., 2017).

In contrast, we found little evidence of DTCA impacting on subsidised medicine dispensing, though it may have an impact on unsubsidised medicines, but there are no public records of these sales. That there is little effect of DTCA on subsidised medicines could be generally expected in a New Zealand context, as government subsidised medicines are substantially cheaper than nonsubsidised medicines (and were a flat $\$ 3$ per medicine for 3 months' supply from 2008). However, if there are even small numbers of people persuaded not to by the cheapest medicines, and if they are some of the most vulnerable, then this is not a good outcome.

This study was limited by the initial screening for magazine titles that may have missed some publications containing DTCA, but is exhaustive for the titles initially identified. The sample itself is now relatively old, but does reflect five full years of medicines advertising. For reasons that are now clouded in time, dispensing data was not sought for a range of medicines (which we hope to update in the near future). The design was also not able to detect changes in nonsubsidised medicines, but that is a limit of most projects using public dispensing data in New Zealand.

Print medicine advertisements in New Zealand 2005-2009 appear to have primarily been used to try to preserve market share when competitor generic medicines were subsidised. This purpose does not benefit the consumer and undermines public good arguments for DTCA, such as that it can serve to educate the consumer.

\section{Acknowledgements}

This first author was supported by a summer studentship funded by the New Zealand Pharmacy Education and Research Foundation (Grant 212b). We would like to thank Lynn Cheong, Andrea Norcross, Aimee Gowler, and Shenal Malde for their help in searching for advertisements, and to the Ministry of Health and PHARMAC for sharing the dispensing data.

\section{References}

Almasi, E. A., Stafford, R. S., Kravitz, R. L., \& Mansfield, P. R. (2006). What Are the Public Health Effects of Direct-to-Consumer Drug Advertising? In (Vol. 3, pp. e145).

Bell, R. A., Wilkes, M. S., \& Kravitz, R. L. (2000). The educational value of consumer-targeted prescription drug print advertising. Journal of Family Practice, 49(12), 1092-1098.

Calfee, J. E. (2002). Public policy issues in direct-to-consumer advertising of prescription drugs. Journal of Public Policy \& Marketing, 21(2), 174-193.

Cheong, L., \& Green, J. A. (2019). Content analysis of direct to consumer prescription medicine advertising in New Zealand. Preprint. 
Colgan, S., Faasse, K., Martin, L. R., Stephens, M. H., Grey, A., \& Petrie, K. J. (2015). Perceptions of generic medication in the general population, doctors and pharmacists: a systematic review. BMJ Open, 5(12), e008915. doi:10.1136/bmjopen-2015-008915

Coney, S. (2002). Direct-to-consumer advertising of prescription pharmaceuticals: A consumer perspective from New Zealand. Journal of Public Policy \& Marketing, 21(2), 213-223.

Frosch, D. L., Grande, D., Tarn, D. M., \& Kravitz, R. L. (2010). A Decade of Controversy: Balancing Policy With Evidence in the Regulation of Prescription Drug Advertising. American Journal of Public Health, 100(1), 24-32. doi:10.2105/ajph.2008.153767

Gilbody, S., Wilson, P., \& Watt, I. (2005). Benefits and harms of direct to consumer advertising: a systematic review. Quality and Safety in Health Care, 14(4), 246-250. doi:10.1136/qshc.2004.012781

Hoek, J. A., \& Maubach, N. (2007). Consumer's knowledge, perceptions, and responsiveness to direct-to-consumer advertising of prescription medicines. New Zealand Medical Journal, 120(1249).

Kaphingst, K. A., DeJong, W., Rudd, R. E., \& Daltroy, L. H. (2004). A content analysis of direct-to-consumer television prescription drug advertisements. Journal of Health Communication, 9(6), 515-528.

Klara, K., Kim, J., \& Ross, J. S. (2018). Direct-to-Consumer Broadcast Advertisements for Pharmaceuticals: Off-Label Promotion and Adherence to FDA Guidelines. Journal of General Internal Medicine, 33(5), 651-658. doi:10.1007/s11606-017-4274-9

Kmietowicz, Z. (2003). New Zealand GPs call for end to direct to consumer advertising. BMJ, 326(7402), 1284.

Lexchin, J., \& Mintzes, B. (2002). Direct-to-consumer advertising of prescription drugs: the evidence says no. Journal of Public Policy \& Marketing, 21(2), 194-201.

Menon, A. M., Deshpande, A. D., Perri, M., \& Zinkhan, G. M. (2003). Consumers' attention to the brief summary in print direct-to-consumer advertisements: Perceived usefulness in patient-physician discussions. Journal of Public Policy \& Marketing, 22(2), 181-191.

Mintzes, B. (2006). Direct-to-consumer advertising of prescription drugs in Canada.

Norris, P., Nelson, L., Ling, K. L., Skellett, L., Hoo, J., Va'ai, C., \& Gates, A. (2005). Advertising of medicines on New Zealand television. New Zealand Medical Journal, 118(1215).

Scott, T., Stanford, N., \& Thompson, D. R. (2004). Killing me softly: myth in pharmaceutical advertising. British Medical Journal, 329(7480), 14841487.

Young, H. N., \& Cline, R. J. W. (2005). Textual cues in direct-to-consumer prescription drug advertising: Motivators to communicate with physicians. Journal of Applied Communication Research, 33(4), 348-369.

Zadeh, N. K., Robertson, K., \& Green, J. A. (2017). 'At-risk'individuals' responses to direct to consumer advertising of prescription drugs: a nationally representative cross-sectional study. BMJ Open, 7(12), e017865. doi:10.1136/bmjopen-2017-017865

Zadeh, N. K., Robertson, K., \& Green, J. A. (2019). Lifestyle determinants of behavioural outcomes triggered by direct-to-consumer advertising of 
prescription medicines: a cross-sectional study. Australian and New Zealand Journal of Public Health, 43(2), 190-196. doi:10.1111/17536405.12883 